\title{
Targeting vulnerable populations: a synthetic review on alcohol use and risky sexual behaviour among migrant populations
}

\author{
Emilia Maria Vaz Martins-Fonteyn ${ }^{1,4^{*}}$, Nina Sommerland ${ }^{1}$, Herman Meulemans ${ }^{1}$, Olivier Degomme ${ }^{2}$, \\ Ines Raimundo ${ }^{3}$ and Edwin Wouters ${ }^{1}$
}

\begin{abstract}
Background: Research has demonstrated a link between alcohol use and risky sexual behaviour among different types of migrant populations. Therefore, research investigating risk factors associated with alcohol consumption among them is a public health priority. This review aimed to explore the intersection between migration, alcohol consumption and risky sexual behaviour.

Methods: This article is a synthetic review of empirical studies on the association of alcohol and high-risk sexual behaviour among different types of the migrant populations, focusing on measurable outcomes generated from quantitative data. A descriptive analysis generated from global and situational studies was used to interpret the reviewed research and to discuss critically the factors that drive migrants to engage in alcohol consumption and high-risk behaviour.
\end{abstract}

Results: This review found out that there is a significant and positive association between global and situational alcohol use and several outcomes of risky sexual behaviour among different types of migrant populations. This association was however mainly observed at high quantities and frequencies of alcohol use, mainly among male migrants, and was often tied to a specific situation or context, for instance the type of sexual partner, the level of mobility and to environmental factors such as living arrangements and entertainment venues.

Conclusions: The study supports previous research that alcohol use is associated with risky sexual behaviour among different types of migrant populations. Therefore, future interventions should target mobile, male migrant heavy drinkers. Additional research is needed using more event-level and longitudinal methodologies that overcome prior methodological limitations.

Keywords: Migrant populations, Alcohol use, Risky sexual behaviour

\section{Background}

The existing theory on the relationship between alcohol consumption and risky sexual behaviour posits that high levels of consumption lead to decreased fear of negative consequences of high risk sexual behaviour [1]. It also shows alcohol consumption has a wide range of consequences in terms of health behaviour and health

\footnotetext{
*Correspondence: emartins2k5@yahoo.com

${ }^{1}$ Department of Sociology, Research Centre for Longitudinal and Life Course Studies, University of Antwerp, University of Antwerp City Campus, Prinsstraat 13, Antwerp, Belgium

Full list of author information is available at the end of the article
}

outcomes, especially when combined with risky sexual behaviour [2-5].

For instance, both acute and chronic alcohol use, as well as the venues where people consume alcohol, can increase the likelihood of risky sexual behaviour. This would include engaging in commercial sex and having multiple sex partners (MSP). These behaviours influence the incidence of HIV infection and other Sexually Transmitted Infections (STIs) [6].

A recent line of research is adding a new stratum to the link between alcohol use and risky sexual behaviour by exploring links among a specific and vulnerable 
population group such as migrants. On the one hand, ample research has linked migrant populations to higher alcohol consumption than the general population [7]. Additionally, migration is increasingly referred to as a significant risk factor for STIs such as HIV [8].

Further, alcohol use behaviours among migrant populations are complex and likely influenced by multiple factors. These include social norms and mental health [9], as well as patterns of migratory process [10].

Since the link between alcohol consumption and risky sexual behaviour has been widely explored in the literature, the aim of this review is to identify the connection between migration, alcohol consumption and risky sexual behaviour. Therefore, the following questions were posed:

Are migrants who consume alcohol more likely to engage in sexual risk behaviour than those who do not? Are alcohol-related sexual risks elevated for the sub-set of migrants than non-migrants? What are the factors among migrants affecting alcohol-related sexual risks?

The better understanding of the association of alcohol use and risky sexual behaviour among migrant populations will assist in developing effective multilevel approaches to mitigate the effects of this combination of risk factors.

\section{Methods}

\section{Eligibility criteria}

A comprehensive literature search was conducted to identify articles meeting the following criteria: empirical articles, measuring the association between alcohol use and an outcome of risky sexual behaviour among migrant populations. Preferred Reporting Items for Systematic Reviews and Meta-Analyses (PRISMA) guidelines were followed. To best assess the influence between alcohol use and risky sexual behaviour, we incorporated quantitative studies. This method was chosen because it is better suited to assess more precise estimates of the group studied. Conversely, qualitative studies are better suited to answering "why" and "how" questions.

In order to evaluate relevant literature, PubMed was searched for English language articles using the following key words: "risk, sexual, behaviour", OR "condom use" OR "multiple partners" OR "sexual transmitted infection STI", AND "alcohol use" OR "abuse", AND "migrant people" OR "population".

From the search process, 7755 articles reported on the period from January 2003 to December 2015 and these were included in the study selection process. After inclusion of the filters on the subjects "AIDS", species "humans" and text availability "full text" in the search process, 343 texts were included in the screening process.

Three steps were applied. In the first phase, the authors independently reviewed all titles of the 343 identified research papers. Of the remaining 137 articles, abstracts were assessed. In the third and final phase, the authors retrieved and reviewed the 22 full-length papers. This enabled our researchers to screen them according to requirements of content. The criteria included providing relevant information concerning the relationship between alcohol abuse and risky sexual behaviour among migrant populations.

As well, quality of the chosen methodology was examined. Questions to be answered were:

1. Are the study design, data collection, data collection methods, sampling strategy and analytical approach appropriate?

2. Is the context described sufficiently, and is the range of missing data acceptable?

In accordance with the methodological requirements of systematic review as specified by Mcrae et al. [11] and Bilotta et al. [12], 19 articles met the inclusion criteria. Additionally, given the first author's extensive prior work on this topic, three articles from past searches were also included.

After excluding articles not meeting the inclusion criteria, this review identified 22 published articles.

\section{Methodology used to relate alcohol-related sexual risks}

This review sought all studies relating to global, situational and event-level-studies of alcohol use linked to any kind of self-reported risky sexual behaviour, among male and female migrant populations. Global studies queries the frequency and quantity of alcohol use as well as the density of drinking establishments in a specified area and correlate with one or more outcomes of risky sexual behaviour.

Some measurements employed in global association studies are the Alcohol Use Identification Test (AUDIT) and binge drinking-more than five drinks in a single drinking occasion. Situational measurements looking into alcohol consumption or being under influence during participants' most recent engagement in sexual intercourse, and finally event-level-studies provide more detailed information regarding specific sexual acts, in which alcohol was consumed [13].

Outcomes of risky sexual behaviour include: unprotected sex, number and type of sexual partners, commercial and premarital sex, STI, and HIV infections.

\section{Results}

Migration and mobility among a population are operationalised differently amongst the studies reviewed. For a better overview, three types of migrant populations were specified in the included studies. The first 
and most commonly studied population with regards to alcohol consumption and risky sexual behaviour were migrant labourers. Many of these could be defined as circular migrants. Common denominators for these populations are they stem from rural surroundings and periodically migrate to cities for economic opportunities. During times when they do not need to work, they typically return to their rural homes and their family/spouses [14].

The second category found in the literature is migrant sex workers. The main reason to distinguish this group from other migrant workers is they do not engage in the same circular pattern of work. As well, they often face a singular kind of vulnerability due to the nature of their occupation.

To the third category belong populations who have permanently migrated to a new country or city. The reason why these populations are studied is that several populations have been discovered to have higher rates of alcohol consumption and STI's than the general population [15].

\section{Characteristics of the sample}

Included in this review are 14 studies of migrant labourers, 2 studies of migrant sex workers and 9 studies of stationary immigrants. The majority, 19 of the populations studied, were male migrant populations. However, few studies focused exclusively upon female migrants and only one study looked at both genders. Overall, the age of the migrant population ranges from 13 to 79 years old.

The majority of articles were found in the USA [7], six in China, three in India and two in Russia, one in Namibia, one in South Africa, one in Bangladesh, and one in Ethiopia. This review found articles presenting very large sample sizes, mostly extracted from large-scale community based household surveys. These included Gupta et al. [10] $(N=174.365)$ and large database from national surveys, e.g. Verma et al. [16] $(N=7.602)$; four studies presented samples from $>5.000$ to $>1000$. The majority of the studies $(60 \%)$ present sample sizes around $>500$ to $>100$.

This review identified 22 quantitative studies, 19 crosssectional, 2 longitudinal, and 1 ecological study, measuring alcohol use and any outcome of risky sexual behaviour among several types of male and female migrant populations. 19 studies used global alcohol measurements and 3 studies used situational measurements.

\section{Alcohol use and unprotected sex}

Global and situational studies presented in this review found a positive association between alcohol use and unprotected sex among migrant labourer population independent of being male or female [17]. Several studies revealed there was a link between alcohol use and non-use of condoms during sex with paid sex workers $[16,18,19]$. However Organista and Kubo [20] did not find any significant associations between alcohol use and unprotected sex with sex workers.

The migrant Female Sex Workers (FSWs) group also shows inconsistent condom use with paid and non-paid partners both significantly higher if they consumed alcohol prior to sex than when they did not [16]. The same result was presented by Wong et al. [21], suggesting migrant Men who have Sex with Men (MSM) or money boys ${ }^{1}$ had sex without a condom because they were under the influence of alcohol. However no statistical tests were performed.

Among stationary migrants, there was a general trend towards a clear-cut association between alcohol consumption and unprotected sex [22, 23]. However, studies looking into migrant MSM did not come to this conclusion. Alcohol intoxication was not significantly associated with condom use/non-use among migrant MSM [24], and when the comparison was made between migrant MSM and general male migrant populations, there was no statistical difference in terms of condom use [25] (Table 1).

\section{Alcohol use and type of sexual partners (paid, non-paid/ casual partners), and premarital sex}

Results among male and female migrant labourers consistently showed a positive association between high consumption of alcohol and engaging in high risk sexual behaviour with numerous types of sexual partners [26, 27]. Migrants who consume alcohol are more prone to engage in sex with any type of partners (paid/non-paid and casual partners) $[10,16,28-30]$.

The population of migrant FSWs also showed a significant relation between alcohol use and sex with three or more casual sex partners [16]. The same result was found among stationary migrants [31, 32] (Table 2).

\section{Alcohol use and STI symptoms and HIV infections}

The three studies focusing upon migrants confirmed the positive association between alcohol consumption and STI and HIV infections [32-34] (Table 3).

\section{Predictors of alcohol use and risky sexual behaviour}

This review identified individual factors such as psychological and behavioural characteristics as predictors of alcohol-related sexual risks. For instance, prior to visiting FSWs, men drink to feel more relaxed [20]. Male migrants who engaged in sex with FSWs were more likely to drink alcohol than those who did not [19].

\footnotetext{
${ }^{1}$ Men who engage in same-sex transactional sex for economic survival.
} 


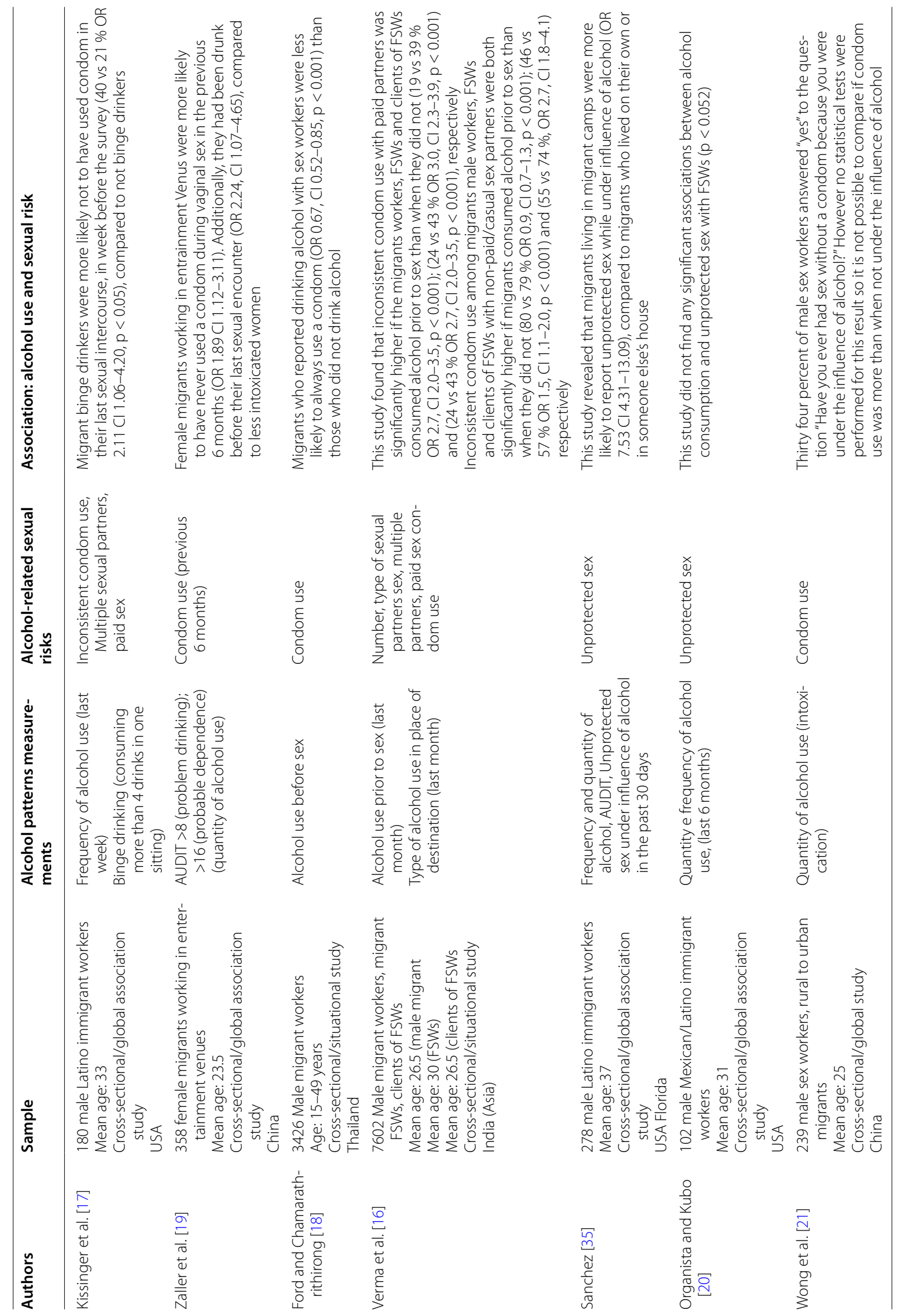




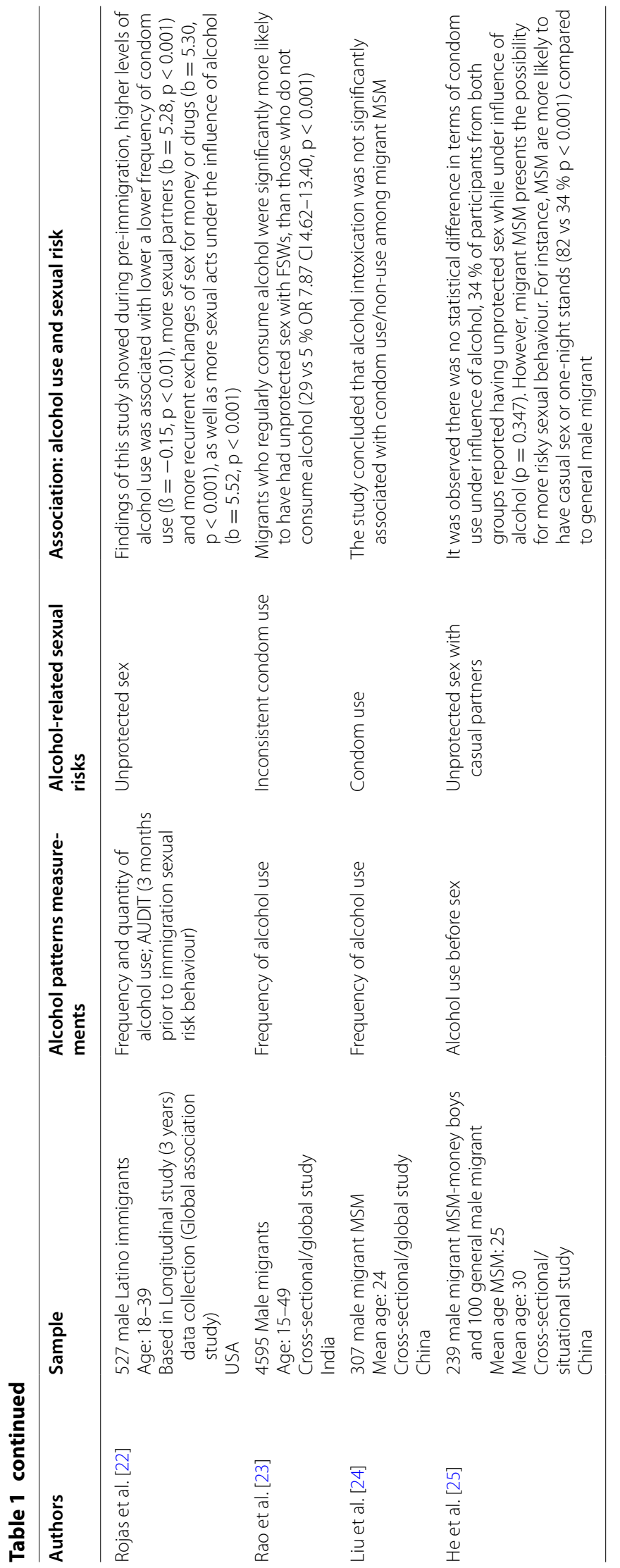




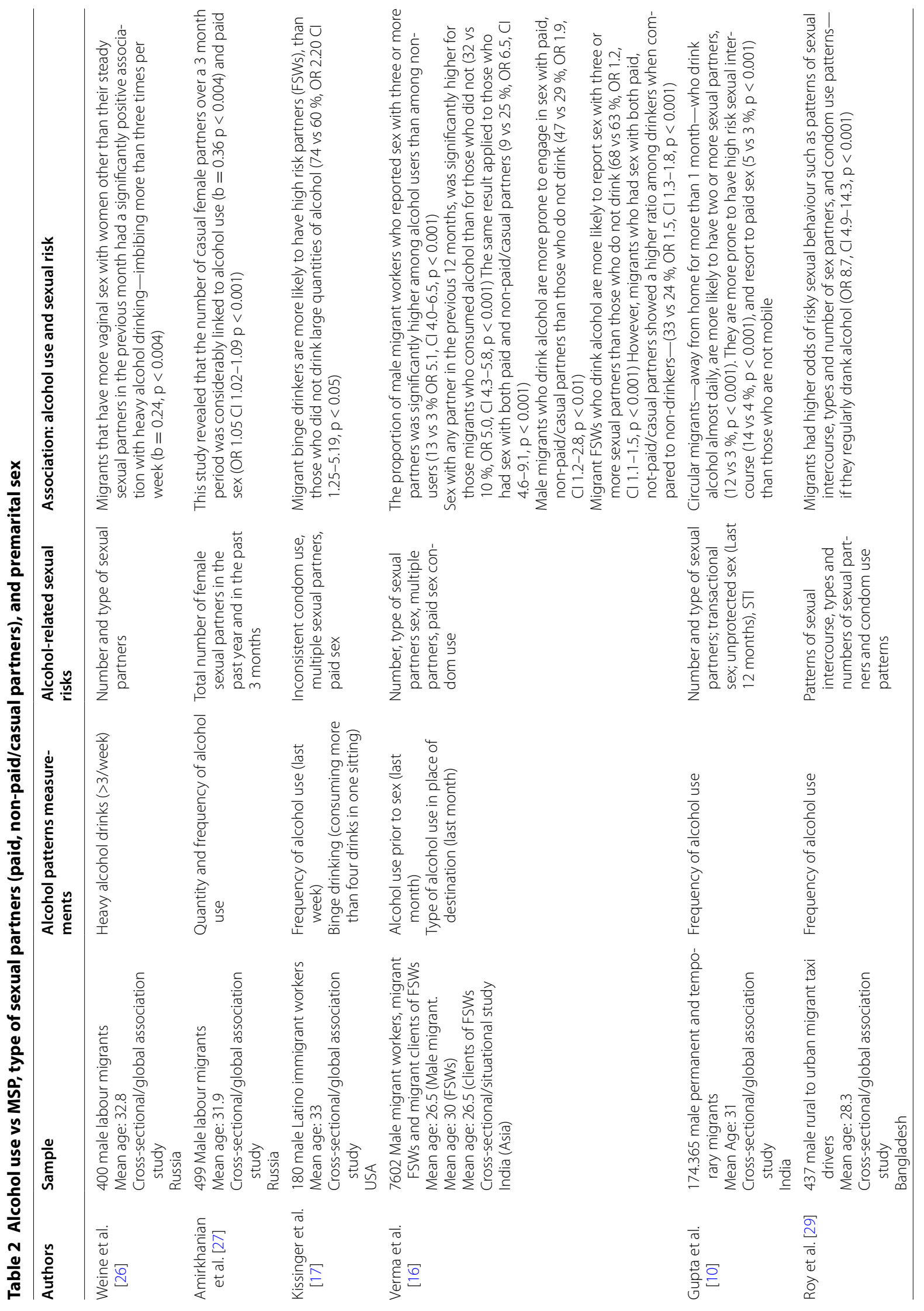




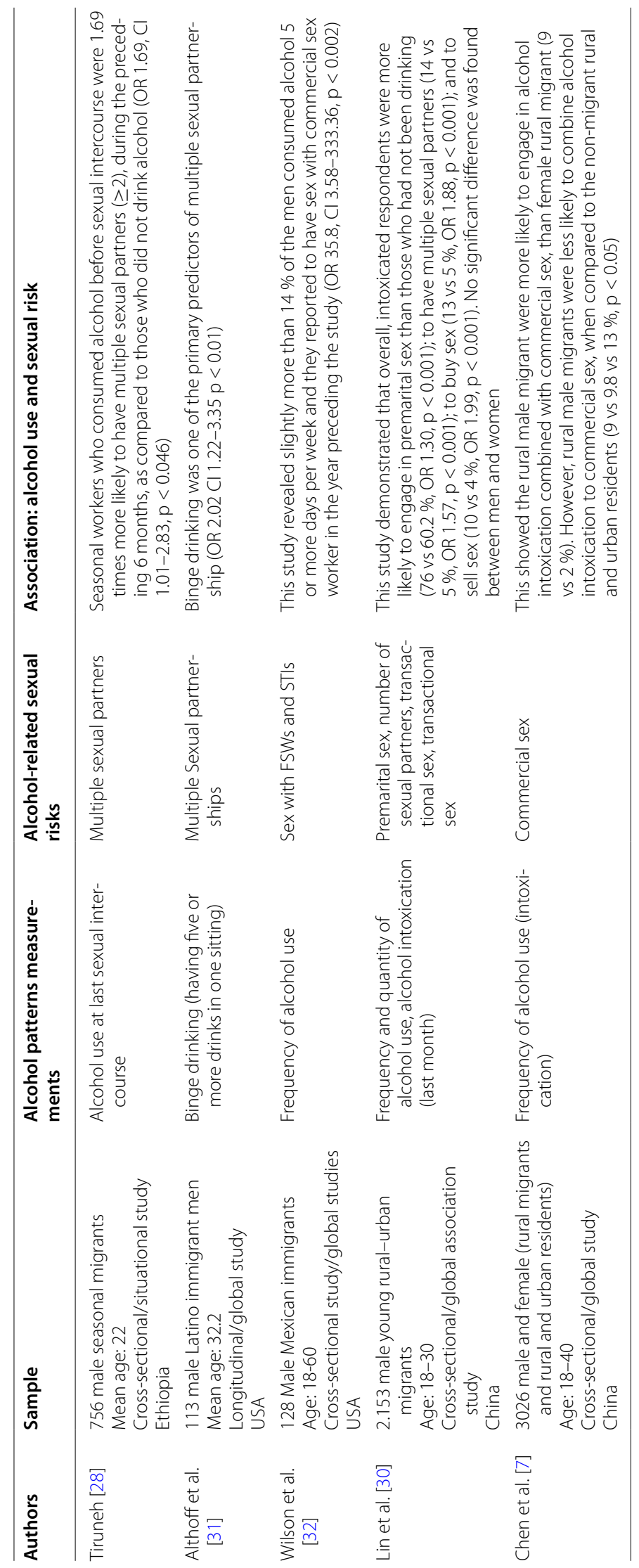




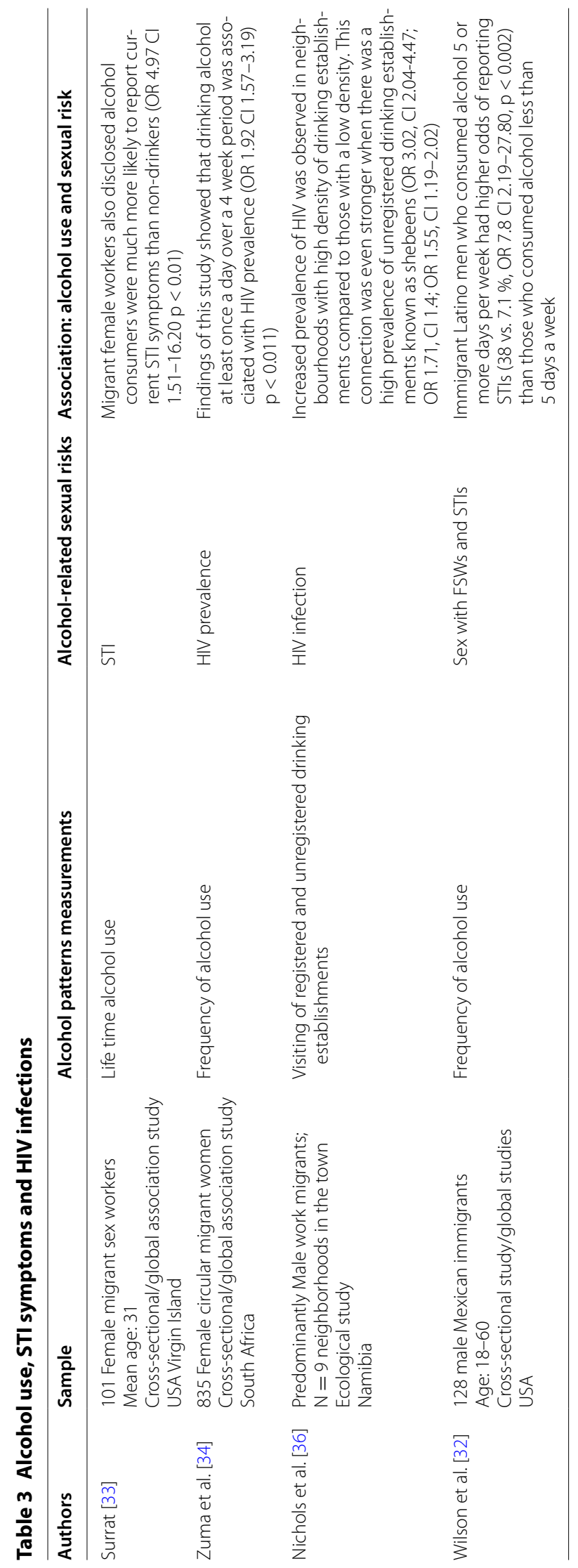


Furthermore, socio-demographic factors, such as younger age, place of residence, and lack of education are also predictors of alcohol use and risky sexual behaviour [27]. For example, less educated migrant FSWs were more prone to engage in alcohol and unprotected sex [33].

Apart from this, environmental factors also seem to be predictors of alcohol-related sexual risks. Weine et al. [26] suggested working and living conditions tend to amplify masculine norms associated with alcoholrelated sexual risks. This includes unprotected sex under influence of alcohol [35]. Moreover, Zaller [19] revealed women working in entertainment venues are more prone to engage in alcohol-related risks than those who do not work in such environments. This occurs independently of them being FSWs or not.

Additionally, increased HIV prevalence was observed in neighbourhoods with a high density of drinking establishments. This connection grew even stronger when there was a higher prevalence of unregistered establishments such as shebeens [36].

Our study also revealed male migrants with a high degree of mobility are more prone to engage in alcoholrelated sexual risks than those who were less mobile. However, among the sub-population of migrant FSWs, high mobility indicated only a minor connection with alcohol-related sexual risk activities $[10,16]$.

Sex workers are considered to be a high-risk group. However, FSWs and their clients as well as MSM money boys, seem not to engage in higher alcohol-related sexual activities than the general migrant population. For instance, high mobility male migrants were more prone to use alcohol prior to sex $(\mathrm{p}<0.001)$, than migrant FSWs ( $\mathrm{p}<0.05)$; and their clients [16]. Additionally, the study by $\mathrm{He}$ et al. [25] did not find any statistical differences between MMS money boys and the general migrant male population.

Finally, we identified that male migrants are more prone to engage in alcohol-related risks than female migrants [7].

\section{Discussion}

We based our analysis on global studies, in which subjects' general patterns of alcohol use are examined in relationship to their typical patterns of sexual behaviour, and that among different types of migrant populations. Our review disclosed the highest odds of reporting risky sexual behaviour such as unprotected sex with FSWs and STIs is among migrants who consumed alcohol frequently and/or heavily [23, 32].

Practices related to sexual intercourse, types and number of sex partners, and patterns of condom use were observed more frequently with migrants who reported drinking alcohol than with those that did not [29]. Studies examining the overall relationship between drinking status and sexual behaviour are limited to describing patterns of general covariation. They do not provide information about the degree to which alcohol use and sexual behaviour occur on the same occasion. Therefore, as such, they cannot inform us about potential causal effects of alcohol upon sexual behaviour [37].

We also based our analysis on situational studies. Clearly, it is important to determine whether alcohol is being consumed proximal to the act of sexual intercourse. Overall, the situational studies in this review, indicated migrants who use alcohol and/or intoxicating substances prior to or during sexual intercourse were more prone to engage in sexually risky behaviour. This included having more unprotected sex, MSP and paid sex, than those who did not drink $[16,18]$.

These studies are somewhat more informative than global studies, as they examine effects from the use of alcohol during sexual events. However, they still obscure the important temporal relationship between alcohol use and risky sexual behaviour. These studies still fail to describe what happens on an event-by-event basis, and thus do not determine whether the occasions characterised by unprotected intercourse were the same occasions during which alcohol was consumed [37].

Apart from that, this literature is composed mostly of cross-sectional studies relying on self-reported alcohol use and sexual behaviour. Findings are therefore constrained in terms of their ability to draw causal conclusions, and all reports of behaviour in this literature must be interpreted with caution.

Only one longitudinal study was found but what this review is most seriously missing are more longitudinally and event level designed studies of the relation between alcohol use and sexual risks. Only with prospective research can temporal associations between alcohol use and sexual risk behaviours be disentangled [38].

However, this review did suggest the link between alcohol use and risky sexual behaviour among migrant populations is an important but under-researched issue all over the world. We were only able to identify 22 articles for our review, and these were concentrated in the USA and China. However, they only focused on the receiving communities with little attention paid to the pre-immigration characteristics of migrant populations or for cultural factors that maybe account for migrants' alcohol use and risky sexual behaviour.

We only found one study that compared pre and post migration HIV risk factors among migrant men and women [35]. It revealed post migration increases migrants' risky sexual behaviour. Both men and women increased their alcohol-related sexual risks while they were in host countries (USA). 
These reviewed studies are also limited in number and scope in relation to the measures of alcohol use and sexual risk behaviour among migrant populations. For example, we only identified three studies conducted in Sub-Saharan Africa. This region carries the world's greatest HIV/AIDS burden, and southern Africa also consumes great quantities of alcohol [2].

Nevertheless, one relevant trend existed among all migrant populations encountered here-labourers, sex workers and stationary immigrants. There was a consistent negative association between alcohol consumption and risky sexual behaviour. Although we did not have the means to compare the different types of the migrant populations in terms of their alcohol-related sexual risks, the study by Verma et al. [16] reveals migrant FSWs and their clients were less likely to engage in alcohol-related sexual activities than male migrants.

The study by He et al. [25] did not encounter any significant difference between MSM money boys and male migrants. These results show the need for future investigation, both observational and interventional, including subpopulations of migrant men and women in diverse geographic locations, and multiple outcomes to assess the link between alcohol use and sexual risk.

Among the studies identified in this review, one rare exception delved into the differences between alcoholrelated sexual risks among migrant and general populations. It revealed that rural male and female migrants were less or equally likely to report alcohol-related risks than rural and urban non-migrants [7]. Furthermore, no significant difference was encountered in comparison to Chinese migrants reviewed by Li et al. [15]. This indicates more research is required on the difference between migrant and non-migrant populations to assess factors contributing to risky sexual behaviour in migratory contexts. Otherwise, there is a risk inaccurate generalisations will be made about migrant populations, when in fact the results only apply to the general population.

\section{Limitations of the review}

We recognise a meta-analysis study would be the best way to correlate the variables in this study. However, migration and mobility were assessed by several measurements-differing socio-economic backgrounds, ages ranging from adolescents to adult, different gender groups, and the regions where studies were conducted. Finally, global and situational measurements of alcohol use and risk behaviour were assessed.

Findings are often limited to global and situational level studies with few experimentally based examinations. Therefore in-depth examination of the specific situation where two behaviours co-occur, the social and cultural context of sexual activity was not researched in sufficient detail.
For instance, neither condom usage during intercourse nor the type of sexual partner-steady or casual-nor the amount of alcohol consumed prior to engaging in sexual activity could be assessed for each and every reported sexual encounter. Moreover, the majority of studies were hampered by their reliance on self-reporting of alcohol consumption and risky sexual behaviour, which is often influenced by social appropriateness.

Furthermore, this review lacks information regarding pre-immigration characteristics of migrant populations, as well as information regarding their communities of origin. This information would be instrumental for comparing former alcohol-related sexual risks in their home environment and the same activities in host communities. Moreover, we recognise specific cultural factors potentially account for certain associations in behavioural patterns.

In addition, the present review is limited by studies published in English and dependent upon availably in the PubMed database.

These limitations notwithstanding, the present literature review provides a broad overview of recent research on alcohol use and risky sexual behaviour among migrant/mobile populations. It also highlights the extent and consistency of significant associations among the variables measured for this type of population.

\section{Conclusions and implications}

This review determined there is a significant and positive association between global and situational alcohol use and several outcomes of risky sexual behaviour among various types of male and female migrant populations. This reveals that migrants should be considered target groups for HIV interventions and strategies.

However, the association between alcohol use and risky sexual behaviour is not linear among the many types of migrant populations. It was mainly observed at high quantities and frequency of alcohol use, mainly in younger male migrants. As well, it was often tied to a specific situation or context. High risk sexual partners, levels of mobility, contextual and environmental factors such as living arrangements, entertainment venues are some of the variables that may increase the likelihood to engage in hazardous alcohol consumption. Thus, this increases the propensity to enter into high risk sexual behaviour. We therefore conclude it is useful to consider risk environments rather than attributing risk to types of people. Consequently, we propose the following recommendations:

Rather than focus on the traditional behavioural science approach which only takes into account individual factors, we suggest broadening it for more comprehensive HIV interventions approaches. These would include 
the structural, environmental, cultural, socio-relational and sexual contexts which create risk environments for migrant populations.

Employers should be encouraged to improve working conditions and provide more family-friendly housing arrangements for migrant workers. Evidence suggests poor working and living conditions amplify masculine norms associated with high risk sexual behaviour including alcohol consumption and engaging with multiple sex partners. Strengthening migrants' capacities for alternative ways of coping with such difficulties could also be a focus of multilevel interventions. For migrant populations, for example, change could be initiated by developing new ways of socialisation including recreational activities. The goal here would be to encourage them to shift away from their traditional notions regarding alcohol use and sexual infidelity [26].

Furthermore, multilevel alcohol Venue-based HIV interventions-that is, interventions targeted at the individual and the settings, such as shebeens [38]-may be required to prevent HIV transmission among migrants. Such interventions would primarily target men who have a high degree of mobility and frequently drink large quantities of alcohol.

Combined approaches such as scientifically proven, cost-effective, and scalable interventions, including biomedical and behavioural interventions represent achievable goals. Additionally, other public health strategies-HIV testing, alcohol and substance abuse treatment programs-are important for reducing HIV transmission among migrants who engage in excessive alcohol consumption [39].

Such approaches need to involve basic research able to identify and link contextual factors to HIV risk in migrants as well as build on the personal agency and resilience of these specific populations [40]. It is also of great importance to further investigate the intersection of population, geographical space or mobile situation together with behaviours of interest, as well as incorporated cultural contexts of migrant populations.

To evaluate the impact of migration on these issues, future studies should also focus on comparing various types of migrant populations, to assess migrants with non-migrants and to provide a theoretical framework on how migration interacts with alcohol consumption and risky sexual behaviour. To measure the possible influential aspects of migration, qualitative methods should be applied when a quantitative approach is not sufficient to explore the underlying influencing factors of migration.

In addition, this review indicates research should use more event level methodologies to better understand how alcohol abuse affects the migrant population's risk behaviour. This would provide stronger evidence and conclusions as to whether or not there is a general causal relationship between alcohol consumption and risky sexual behaviour among migrant populations.

\section{Authors' contributions}

EMF contributed to the study design, analysed the data, drafted the manuscript, interpreted the results and wrote the manuscript. NS contributed to data analysis, the interpretation of results and to the writing of the manuscript. HM contributed to the study design, data analysis and critical revision of the manuscript. OD contributed to the study design, data analysis and critical revision of the manuscript. IR contributed to the critical revision of the manuscript. EW contributed to the study design, data analysis, interpretation of results and to the critical revision of the manuscript. All authors read and approved the final manuscript.

\section{Authors' information}

EMF is enrolled in a Ph.D. program in Sociology through the University of Antwerp, has received a Master in Evaluation and Management of Development Policies, at the Institute of Development Policy (IOB), University of Antwerp, and a Master in Rural Development at the University Eduardo Mondlane. She has more than ten year's research experience in Mozambique, with a particular emphasis on HIV and AIDS. At the Ministry of Science and Technology she oversees all operational research conducted under the Multi-sectorial National Strategic Plan to Fight HIV/AIDS (PEN III).

NS is a Ph.D. candidate in the field of medical sociology. She holds a Master of Science in sociology from Stockholm University, and specialises in HIV and TB stigma among healthcare workers in South Africa. She has previously undertaken social research on alcohol and substance abuse at the Swedish Council for information of Alcohol and Other Drugs (CAN).

HM studied at the University of Antwerp, Belgium, where he obtained his bachelor in sociology, bachelor in economics, master of arts and Ph.D. in sociology. He was research associate at Boston University and received the GLAXO Award for Science Journalism. Most recently, he was a professor in quantitative research methods and medical sociology at the Faculty of Social and Political Sciences, chair of the Master Programme in Social Work, University of Antwerp. He was also a research associate at the CHSR\&D, University of the Free State, South Africa. He is an author and co-author of more than two hundred journal articles, research reports and books on social policy, social engineering, services in the social \& health sectors, professions, organisations and global health. He has been chair of the department of sociology, vice-dean of the faculty of social and political sciences, chair of the educational commission and of the VLIR-visitation commission socio-medical sciences and gerontology. He is member of the board of several non-profit organizations.

$\mathrm{OD}$ is the Scientific Director of International Centre for Reproductive Health (ICRH). He obtained a medical degree at Ghent University in 2004 He subsequently obtained a Master's in Public Health from the Université Catholique de Louvain (UCL) and began working at the Centre for Research on the Epidemiology of Disasters (CRED) based at UCL. He was in charge of the centre's conflict research team whose main activity was the creation and maintenance of the Complex Emergency Database. In addition, he was involved in several projects investigating health and mortality among conflict affected populations. For this, he conducted research in several countries including Sudan, Ghana and Thailand. He completed his Ph.D. in health sciences on mortality patterns in the Darfur conflict between 2003 and 2008. His special interests are epidemiological methods and techniques, international public health and health in humanitarian settings.

IR is in charge of Post-Graduate studies as the Deputy-Dean at the Faculty of Arts and Social Sciences of Eduardo Mondlane University (UEM). She holds a Ph.D. in Forced Migration and a Master in Human Geography from the University of Witwatersrand, Johannesburg, South Africa. In the past 19 years at UEM she has been involved in projects on population mobility, sexual reproductive health, poverty, HIV/AIDS, urbanisation and food security. Furthermore, her research includes an analysis of the socio-economic and cultural factors leading to miners' vulnerability to HIV infection. She has worked as co-researcher with several institutions across Southern Africa such as SAMP (Southern African Migration project) and AFSUN (African Food Security Urban Network). With SAMP, she coordinated the Women Cross Border Traders and HIV/Risk study. She was co-coordinator of the Men's Migration and Women's HIV/AIDS Risks project in Mozambique (NIH/NICHD 1R21HD048257-01A1), with Arizona State University and the former Centre for Population Studies of UEM. 
EW is an assistant professor in Medical Sociology at the Faculty of Political and Social Sciences of the University of Antwerp (Belgium). His research mainly focuses on the social aspects of health and illness. More specifically, he has published on HIV/AIDS, mental health, tuberculosis, health systems and health policy in the developed world as well as in developing countries such as South Africa.

\section{Author details}

1 Department of Sociology, Research Centre for Longitudinal and Life Course Studies, University of Antwerp, University of Antwerp City Campus, Prinsstraat 13, Antwerp, Belgium. ${ }^{2}$ International Centre for Reproductive Health, Ghent University, Ghent, Belgium. ${ }^{3}$ Faculty of Social Sciences, University Eduardo Mondlane, Maputo, Mozambique. ${ }^{4}$ Linde, 10, 1840 Londerzeel, Belgium.

\section{Acknowledgements}

The authors appreciatively acknowledge the sponsors of this study: the Ministry of Science and Technology, through the World Bank Project.

The authors gratefully acknowledge the contribution of the reviewers, which led to an improved version of this manuscript.

The views expressed here are those of the authors and do not necessary reflect official policy or positions of the sponsor institutions.

\section{Competing interests}

The authors declare that they have no competing interests.

Received: 8 February 2016 Accepted: 12 September 2016

Published online: 22 September 2016

\section{References}

1. Woolf-king S, Maisto S. Alcohol use and high-risk sexual behaviour in Sub-Saharan Africa: a narrative review. Arch Sex Behav. 2011:40:17-24

2. Scott-Sheldon L, Carey M, Carey K, Cain D, Harel O, Mehlomakulu V, Mwaba K, Simbayi L, Kalichman S. Patternes of alcohol use and sexual behaviors among current drinkers in Cape Town, South Africa. Addict Behav. 2012:37:492-7.

3. Cain D, Pare V, Kalichman S, Harel O, Mthembu J, Carey M, Carey K, Mehlomakulu V, Simbayi L, Mwaba K. HIV risks associated with patronizing alcohol serving establishments in South African Townships, Cape Town. Prev Sci. 2012;13:627-34.

4. Townsend L, Rosenthal S, Parry C, Zembe Y, Mathews C, Flisher A. Associations between alcohol misuse and risks for HIV infection among men who have multiple female sexual partners in Cape Town, South Africa. AIDS Care. 2010;22(Suppl 12):1544-54.

5. Townsend L, Ragnarsson A, Mathews C, Johnston L, Ekström A, Thorson A, Chopra M. "Taking care of business": alcohol as currency in transactional sexual relationships among players in Cape Town, South Africa. Qual Health Res. Online. 2010. http://www.sagepublications.com. Accessed 3 Sept 2013.

6. Bryant K, Nelson S, Braithwaite RS, Roach D. Integrating HIV/AIDS and alcohol research. Alcohol Res Health. 2010;33(Suppl):3.

7. Chen CH, Stanton B, Li X, Fang X, Lin D, Xiong Q. A comparison of healthrisk behaviors of rural migrants with rural residents and urban residents in China. Am J Health Behav. 2009:33(Suppl 1):15-25.

8. Crush J, Raimundo I, Simelane, H, Cau B, Dorey D. Migration-induced HIV and AIDS in rural Mozambique and Swaziland. SAMP Migr Policy. 2010;53.

9. Zuniga ML, Fisher PL, Cornelius D, Cornelius W, Goldenberg SH, Keys D. A transnational approach to understanding indicators of mental health, alcohol use, and reproductive health among indigenous Mexican migrants. J Immigr Minor Health. 2014;16:329-39.

10. Gupta K, Vaidehi Y, Majumber N. Spatial mobility, alcohol use, sexual behaviour and sexual health among males in India. AIDS Behav. 2010;14:18-30.

11. McCrae N, Blackstock M, Purssell E. Eligibility criteria in systematic reviews: a methodological review. Int J Nurs Stud. 2015. http://www.dx.doi. org/10.1016/j.jinurstu. Accessed 2 Feb 2015.

12. Bilotta G, Milner A, Boyd I. On the use of systematic reviews to inform environmental policies. Environ Sci Policy. 2014;42:67-77.
13. Weinhardt L, Carey M. Does alcohol lead to sexual risk behavior? findings from event-level research. Ann Rev Sex Res. 2000;11(Suppl 1):125-57.

14. Campbell C. Migrancy masculine identities and AIDS: the psychosocial context of the HIV transmission on the South African gold mines. Soc Sci Med. 1997;45(Suppl 2):273-81.

15. Li Q, Li X, Stanton B. Alcohol use and sexual risk behaviors and outcomes in China: a literature review. AIDS Behav. 2010;14:1227-36.

16. Verma R, Saggurti N, Singh A, Swain S. Alcohol and sexual risk behavior among migrant female sex workers and male workers in districts with high in-migration from four high HIV prevalence states in India. AIDS Behav. 2010;14:31-9.

17. Kissinger P, Liddon N, Schmidt N, Curtin E, Salinas O, Navarez A. HIV/STIrisk behaviour among latino migrant workers in New Orleans Post-Hurricane Katrina disaster. Sex Transm Dis. 2008;32(Suppl 11):924-9.

18. Ford K, Chamrathrithirong A. Sexual partners and condom use of migrant workers in Thailand. AIDS Behav. 2007:11:905-14.

19. Zaller N, Huang W, He H, Dong Y, Song D, Zhang H, Operario D. Risky alcohol use among migrant women in entertainment venues in China. Alcohol Alcohol. 2010;49(Suppl):3.

20. Organista K, Kubo A. Pilot survey of HIV risk and contextual problems and issues in Mexican/Latino migrant day laborers. J Immigr Health. 2005;7(Suppl):4

21. Wong FY, Huang ZJ, He N, Smith BD, Ding Y, Fu C, Young D. HIV risks among gay and non-gay identified migrant money boys in Shanghai, China. AIDS Care Psychol Socio Med Asp AIDS/HIV. 2008;20(Suppl 2):170-80.

22. Rojas P, Dillon F, Cyrus E, Ravelo G, Malow R, De La Rosa M. Alcohol use as a determinant of HIV risk behaviors among recent latino immigrants in South Florida. J Assoc Nurses AIDS Care. 2014;25(Suppl 2):135-44.

23. Rao N, Jeyasselan L, Joy A, Sampath Kamur V, Thenmozhi M, Acharya S. Factors associated with high-risk behaviour among migrants in the State of Maharashtra. J Biosoc Sci. 2013;45:627-41.

24. Liu Y, Li X, Zhang L, Li SH, Jiang SH, Stanton B. Correlates of consistent condom use among young migrant men who have sex with men (MSM) in Beijing, China. Eur J Contracept Reprod Health Care. 2012;17:219-28.

25. He N, Wong FY, Huang ZJ, Ding Y, Fu CH, Smith B, Young D, Jiang Q. HIV risks among two types of male migrants in Shanghai, China: money boys vs. general male migrants. AIDS. 2007;21(Suppl 8):73-9.

26. Weine S, Bahromov M, Loue S, Owens L. HIVsexual risk behaviors and multilevel determinants among male labor migrants from Tajikstan. J Immigr Minor Health. 2013;15:700-10.

27. Amirkhanian Y, Kuznetsova A, Kelly J, DiFranceisco W, Musatov V, Avsukevich N, Chaika N, McAuliffe T. Male labor migrants in Russia: HIV risk behaviour levels, contextual factors, and prevention needs. J Immigr Minor Health. 2011;13:919-28.

28. Tiruneh K, Wasie B, Gonzalez H. Sexual behavior and vulnerability to HIV infection among seasonal migrant laborers in Metema district, northwest Ethiopia: a cross-sectional study. BMC Publ Health. 2015;15:122.

29. Roy T, Anderson C, Evans C, Rehman MS. Sexual risk behaviour of ruralto-urban migrant taxi drivers in Dhaka, Bangladesh: a cross-sectional behavioural survey. Publ Health. 2010;124:648-58.

30. Lin D, Li X, Yang H, Fang X, Stanton B, Chen X, Abbey A, Liu H. Alcohol intoxication and sexual risk behaviors among rural-to-urban migrants in China. Drug Alcohol Depend. 2005;79(Suppl 1):103-12.

31. Althoff MD, Anderson-Smits C, Kovacs S, Salinas O, Hembling J, Schmidt $\mathrm{N}$, Kassinger P. Patterns and predictors of multiple sexual partnerships among newly arrived Latino migrant men. AIDS Behav. 2013;17:2416-25.

32. Wilson K, Eggleston E, Diaz-Olavarrieta CH, Garcia S. HIV/STI risk among male Mexican immigrants in Dallas, Texas: findings from a Pilot Study. J Immigr Minor Health. 2010;12:947-51.

33. Surrat H. Sex work in Caribbean Basin: patterns of substance use and HIV risk among migrant sex workers in the US Virgin Islands. AIDS Care Psychol Socio Med Asp AIDS/HIV. 2007;19(Suppl 10):1274-82.

34. Zuma K, Gouws E, Williams B, Lurie M. Risk factors for HIV infection among women in Carletonville, South Africa: migration, demography and sexually transmitted diseases. Int J STD AID. 2003;14:814-7.

35. Sanchez J. Alcohol use among Latino migrant workers in South Florida. Drug Alcohol Depend. 2015;151:241-9.

36. Nichols B, Nkalamo D, Whitcomb B. Density of drinking establishments and HIV prevalence in a migrant town in Namibia. AIDS Behav. 2012;16:829-34. 
37. Halpern-Felsher B, Millstein S, Ellen J. Relationship of alcohol use and risky sexual behaviour: a review and analysis of findings. J Adolesc Health. 1994;19:331-6.

38. Kalichman S, Simbayi L, Kaufman M, Cain D, Jooste S. Alcohol use and sexual risks for HIV/AIDS in Sub-Saharan Africa: systematic review of empirical findings. Prev Sci. 2007;8:141-51.
39. Hess K, Chavez P, Kanny D, DiNenno E, Lansky A, Paz-Bailey G. Binge drinking and risky sexual behavior among HIV-negative and unknown HIV status men who have sex with men, 20 US cities. Drug Alcohol Depend. 2015;147:46-52.

40. Organista K, Carrillo H, Ayala G. HIV prevention with Mexican migrants: review, critique, and recommendations. J Acquir Immune Defic Syndr. 2004;37(Suppl 4):S227-39.

\section{Submit your next manuscript to BioMed Central} and we will help you at every step:

- We accept pre-submission inquiries

- Our selector tool helps you to find the most relevant journal

- We provide round the clock customer support

- Convenient online submission

- Thorough peer review

- Inclusion in PubMed and all major indexing services

- Maximum visibility for your research

Submit your manuscript at www.biomedcentral.com/submit 